\title{
The Upper Boundary of the Subducting Pacific Plate Estimated from ScSp Waves beneath the Kanto Region, Japan
}

\author{
Takashi lidaka $^{1, *}$ and Kazushige Obara ${ }^{2}$ \\ ${ }^{1}$ Earthquake Research Institute, the University of Tokyo, \\ Bunkyo-ku, Tokyo 113, Japan \\ ${ }^{2}$ National Research Institute for Earth Science \\ and Disaster Prevention, Tsukuba 305, Japan
}

Subducting slabs with seismic velocities and $Q$ values larger than the surrounding mantle are general characteristics of island arc regions. Beneath Japan, subduction of both the Pacific and Philippine Sea plates occurs. The general configuration of the subducting plates in the Kanto-Tokai district on Honshu Island, Japan, has been mapped by examining the spatial distribution of microearthquakes and estimated from three-dimensional inversions for body wave velocity structure (e.g., Ishida and Hasemi, 1988; Ishida, 1992). The upper boundary of the subducting slab has previously been detected by the analyses of converted waves (Okada, 1971; Hasegawa et al., 1978; Nakanishi et al., 1981; Matsuzawa et al., 1986; Obara and Sato, 1988; lidaka et al., 1989; Obara, 1989).

Analysis of the ScSp wave, which is an $\mathrm{ScS}$ to $\mathrm{P}$ converted wave at the upper boundary of slab, has also been used to locate the upper boundary of the descending oceanic plate (Okada, 1971; Hasegawa et al., 1978; Nakanishi et al., 1981). In the Kanto region, the ScSp converted wave was previously observed at three seismic stations in the northern 'Kanto region (Nakanishi et al., 1981), but due to the lack of spatiallydense seismic networks delineation of the iso-depth lines of the subducting Pacific plate was precluded. Recently, however, spatially-dense seismic networks have been established in the Kanto-Tokai region by NIED (National Research Institute for Earch Science and Disaster Prevention) and ERI (Earthquake Research Institute, the University of Tokyo), thus making it possible to map the upper boundary of the subducting Pacific slab using ScSp wave data. In this study, we use ScSp wave data from a large, deep earthquake beneath Sakhalin Island to estimate the location of the Pacific slab upper boundary in the Kanto region.

The data for this study come from a large deep earthquake which occurred on 12 May 1990 beneath Sakhalin Island. The body wave magnitude for this event was 6.5 and hypocentral parameters estimated by the ISC (International Seismological Center) were $49.05^{\circ} \mathrm{N}, 141.88^{\circ} \mathrm{E}$ and $603 \mathrm{~km}$ depth. The seismometers used in this study are $1 \mathrm{~Hz}$ velocity types. A clear precursor phase ( $\mathrm{X}$ phase) to the $\mathrm{ScS}$ phase can be observed on the vertical component records of seven among the 70 seismic stations that the $\mathrm{ScS}$

Received May 6, 1993; Accepted May 22, 1993

* To whom correspondence should be addressed. 


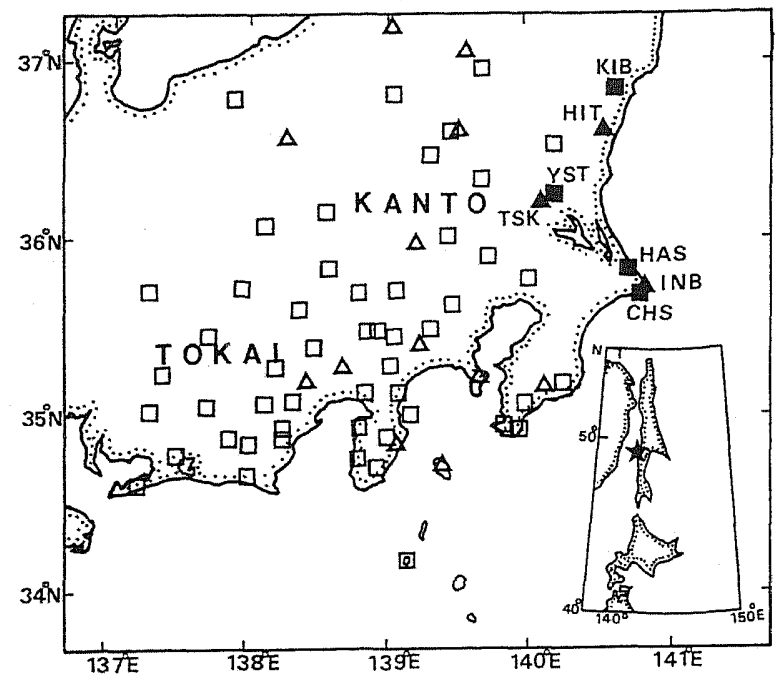

Fig. 1. Distribution of seismic stations of NIED (squares) and ERI (triangles) in central Honshu Island, Japan. The solid and open symbols denote the seismic stations where the $\mathrm{X}$ phase is and is not observed, respectively. The location of the earthquake (solid star) used in this study is shown in the inset.

Table 1. Differential time between $T_{\mathrm{scs}}-T_{\text {scSp }}$.

\begin{tabular}{|c|c|c|c|}
\hline \multirow{2}{*}{ Station name } & \multicolumn{2}{|c|}{ Location (deg.) } & \multirow{2}{*}{$\begin{array}{c}\text { Differential time } \\
\text { (s) }\end{array}$} \\
\hline & Latitude N & Longitude $\mathrm{E}$ & \\
\hline CHS (NIED) & 35.7022 & 140.8550 & 2.7 \\
\hline HAS (NIED) & 35.8259 & 140.7355 & 3.6 \\
\hline HIT (ERI) & 36.6182 & 140.5902 & 8.2 \\
\hline INB (ERI) & 35.7019 & 140.8590 & 2.9 \\
\hline KIB (NIED) & 36.8777 & 140.6578 & 8.0 \\
\hline TSK (ERI) & 36.2109 & 140.1042 & 7.3 \\
\hline YST (NIED) & 36.2530 & 140.2061 & 8.1 \\
\hline
\end{tabular}

phase could be clearly seen on the horizontal components (Figs. 1, 2). The X phase can be observed at seismic stations CHS, HAS, HIT, INB, KIB, TSK, and YST, which are located in the northeastern Kanto region (Fig. 1). The $\mathrm{X}$ phase has the following characteristics:

(1) The X phase is clearly observed on the vertical component records. This feature implies that the $\mathrm{X}$ wave (X phase on the seismograms) corresponds to a $\mathrm{P}$ wave.

(2) The differential travel time $T_{\mathrm{ScS}}-T_{\mathrm{X}}$ increases as the station location shifts to the inner part of the island arc (Table 1). This feature implies that the conversion depth increases to the northwest in the Kanto region.

(3) The dominant particle motion of the ScS phase is in the N-S direction (Fig. 3). However, the horizontal particle motion of the $X$ phase (Fig. 3) is predominantly 

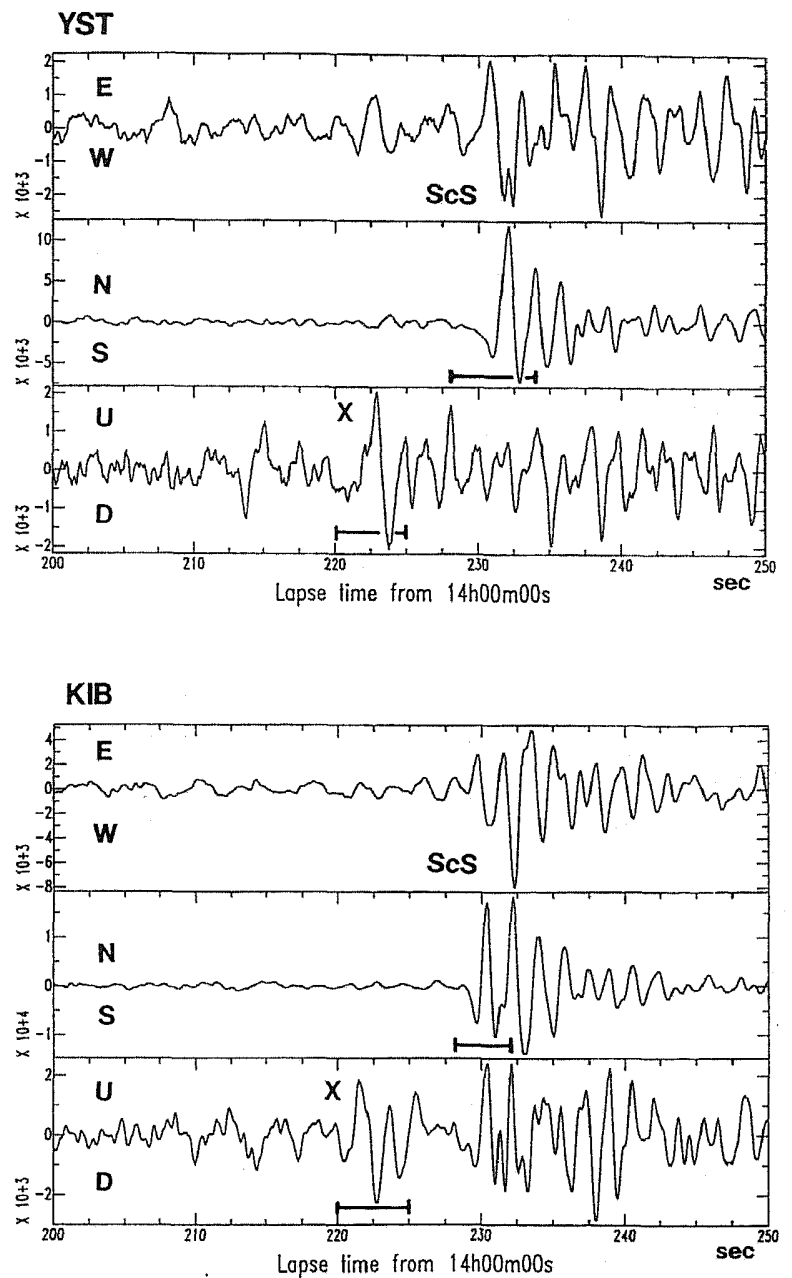

Fig. 2. Examples of three-component seismograms from stations, YST and KIB. EW and NS are horizontal component records, and UD is the vertical component record. The particle motions for the periods shown by bar are shown in Fig. 3.

in the NW-SE direction. Particle motions for the precursor phase at the five other stations listed in Table 1 also trend northwest-southeast.

These characteristics are very similar to those of ScSp wave (Okada, 1971). We estimated the location of the converted boundary as the $\mathrm{X}$ wave is assumed to be the $\mathrm{ScSp}$ wave. We determine the location of the ScS-to-P conversion interface from the differential travel time, $T_{\text {Scs }}-T_{\text {Scsp }}$, following the techniques employed by Okada (1971), Snoke et al. (1977), and Nakanishi et al. (1981): (1) we assume that the conversion points are located on a plane; (2) the strike of the converted boundary is determined 

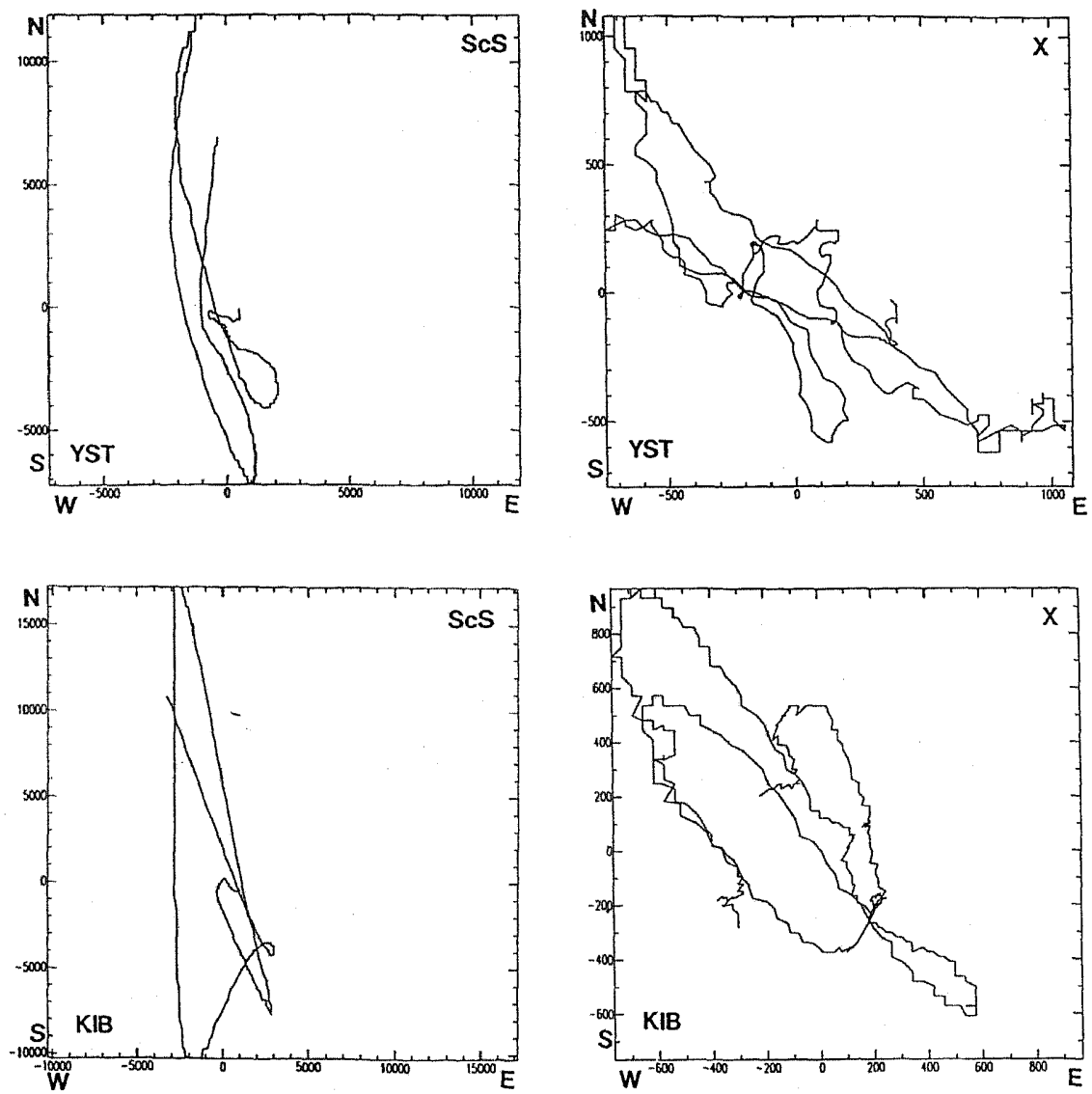

Fig. 3. Horizontal-component particle motions of the $\mathrm{ScS}$ and $\mathrm{X}$ phases. The particle motion of the ScS phase trends north-south, while that of the X phase shows a northwest-southeast direction. The direction of the $\mathrm{X}$ phase almost parallels the dip direction of the subducting Pacific plate.

from the differential travel time data; (3) the conversion are determined by changing the dip angle of the boundary on the vertical cross section at the dip direction; (4) the converted boundary is obtained when the estimated dip angle from observed data fits the assumed dip angle. Iso-differential travel time lines are calculated using a velocity model proposed by Ukawa et al. (1984) (shallower than $400 \mathrm{~km}$ ) and Jeffreys and Bullen (1940) (deeper than $400 \mathrm{~km}$ ).

The obtained boundary dips to the northwest direction with a dip angle of 28 degrees (Fig. 4). The direction is the same direction of dip of subducting Pacific plate. The converted boundary is obtained from 35 to $100 \mathrm{~km}$ in depth. The conversion points are located at the depths of $35-50$ and $80-100 \mathrm{~km}$ in the central and northern Kanto regions, respectively. We interpret the $\mathrm{X}$ wave as the $\mathrm{ScS}$ to $\mathrm{P}$ converted phase at the upper boundary of the subducting Pacific slab. 


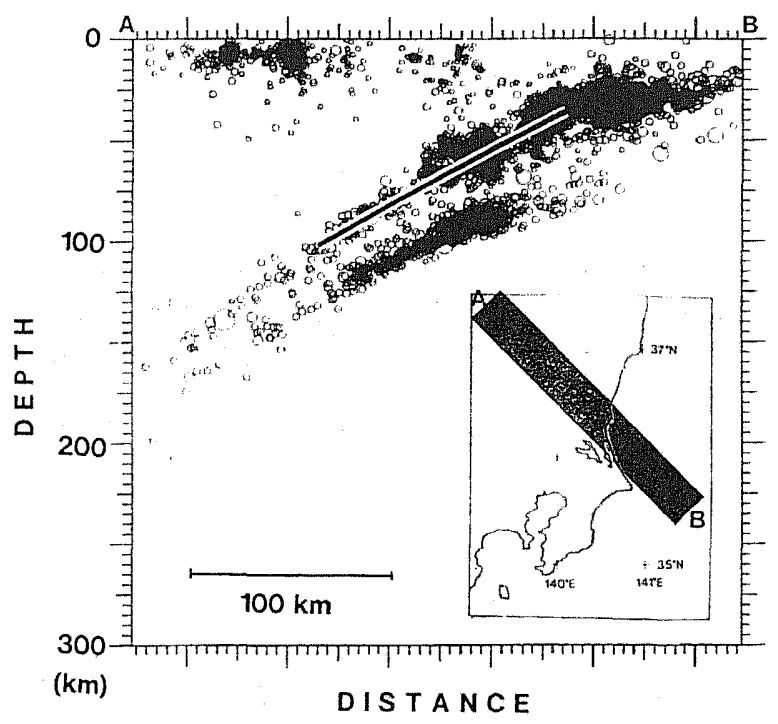

Fig. 4. Vertical cross section for the shaded area shown in the inset. The upper boundary of the subducting Pacific slab estimated from ScSp data is shown by the solid line. The locations of microearthquakes delineating the doubleplaned seismic zone are also plotted.

The location of the upper boundary of the Pacific slab has also been obtained using $\mathrm{P}$ to $\mathrm{S}$ converted waves (Iidaka $e t$ al., 1989) and using reflected $\mathrm{S}$ waves (Obara, 1989 ) in the northeastern and northern Kanto regions, respectively. The iso-depth lines obtained from ScSp data in this study are consistent with those of Iidaka et al. (1989), but inconsistent with those of Obara (1989) which were determined to be about $10 \mathrm{~km}$ shallower than those of our study. The obtained dip angle are slightly different from the angle of about 25 degrees obtained from seismicity map (Ishida, 1992). Based on a comparison with NIED microearthquake locations, the conversion boundary determined in this study appears to correspond to the upper seismic plane of the double-planed deep seismic zone (Fig. 4). This conclusion appears to be inconsistent with that suggested by previous authors who found that the upper boundary to be just above the upper seismic plane (e.g., Matsuzawa et al., 1986; Obara, 1989). The resolution of this study is not enough to resolve this discrepancy because of the uncertainties mentioned below.

Location errors of the boundary are thought to be about $10 \mathrm{~km}$ due to uncertainties in the velocity model used for the calculation. Further, because three plates (Pacific, Eurasian, and Philippine Sea plates) converge beneath the Kanto region, a more exact depth location of the subducting Pacific slab requires the use of a three-dimensional velocity structure model to locate the boundary.

The $\mathrm{ScSp}$ wave is clearly observed only in the northern Kanto region, and not in the southern Kanto and Tokai regions. The dip direction of the subducting Pacific slab is estimated to be roughly $\mathrm{NW}$ and $\mathrm{W}$ in the northern and southern parts of Kanto 
region, respectively (Ishida, 1992). In the southern Kanto region, this is thought to result from the parallel directions of the iso-depth line of the subducting Pacific plate with the horizontal particle motion direction of the ScS wave. A low degree of ScS-to-P conversion efficiency is thus expected.

We are grateful to Dr. Y. Okada for his support in accomplishing this study. We wish to thank Profs. K. Abe, and M. Mizoue who kindly provided the seismograms from the seismic stations of the Earthquake Research Institute, the University of Tokyo. We wish to thank Dr. N. Hurukawa (a referee of this paper) who advised us on process of analysis. We also thank Dr. R. J. Geller and Dr. Laura Kong for critically reading this manuscript. This research was supported by a grant from the Ministry of Education, Science and Culture of Japan (No. 02952098).

\section{REFERENCES}

Hasegawa, A., N. Umino, and A. Takagi, Double-planed deep seismic zone and upper-mantle structure in the Northeastern Japan Arc, Geophys. J. R. Astron. Soc., 54, 281-296, 1978.

lidaka, T., I. Nakamura, and M. Mizoue, The upper boundary of the Pacific plate beneath the Kanto region estimated from PS converted waves, Bull. Earthq. Res. Inst., Univ. Tokyo, 64, 37-50, 1989 (in Japañese).

Ishida, M., Geometry and relative motion of the Philippine Sea plate and Pacific plate beneath the Kanto-Tokai District, Japan, J. Geophys. Res., 97, 489-513; 1992.

Ishida, M. and A. Hasemi, Three-dimensional fine velocity structure and hypocentral distribution of earthquakes beneath the Kanto-Tokai district, Japan, J. Geophys. Res., 93, 2076-2094, 1988.

Jeffreys, H. and K. E. Bullen, Seismological Tables, British Association for the Advancement of Science, Gray Milne Trust, London, pp. 1-50, 1940.

Matsuzawa, T., N. Umino, A. Hasegawa, and A. Takagi, Upper mantle velocity structure estimated from PS-converted wave beneath the north-eastern Japan Arc. Geophys. J. R. Astron. Soc., 86, 767-787, 1986.

Nakanishi, I., K. Suyehiro, and T. Yokota, Regional variations of amplitudes of ScSp phases observed in the Japanese Islands, Geophys. J. R. Astron. Soc., 67, 615-634, 1981.

Obara, K., Regional extent of the S wave reflector beneath the Kanto district, Japan, Geophys. Res. Lett., 16, 839-842, 1989.

Obara, K. and H. Sato, Existence of an S wave reflector near the upper plane of the double seismic zone beneath the southern Kanto district, Japan, J. Geophys. Res., 93, 15037-15045, 1988.

Okada, H., Forerunners of ScS waves from nearby deep earthquakes and upper mantle structure in Hokkaido, Zisin, 24, 228-239, 1971 (in Japanese).

Snoke, J. A., I. S. Sacks, and H. Okada, Determination of the subducting lithosphere boundary by use of converted phases, Bull. Seismol. Soc. Am., 67, 1051-1060, 1977.

Ukawa, M., M. Ishida, S. Matsumura, and K. Kasahara, Hypocenter determination method of the Kanto-Tokai observational network for microearthquakes, in Res. Notes NRCDP 53, pp 1-88, National Research Center for Disaster Prevention, Tsukuba, 1984 (in Japanese). 